Kiryoku, Volume 2 No 4, 2018

e-ISSN:2581-0960 p-ISSN: 2599-0497

Tersedia online di http://ejournal.undip.ac.id/index.php/kiryoku

\title{
DAMPAK PENERAPAN PERUBAHAN SISTEM PENDIDIKAN SMA DALAM ANIME KOKURIKO-ZAKA KARA
}

\author{
Fajria Noviana*, Budi Mulyadi \\ Universitas Diponegoro \\ Email: fajrianoviana0701@gmail.com
}

\begin{abstract}
(Title: The Impact of Implementing Changes in High School Education System in Kokuriko-zaka Kara Anime) This anime tells story about Konan High School students who fight to protect an old building, which has become a center for their activities, from destruction by school owner. The purpose of this paper is to explain the impact of implementing changes in Japan'sHigh School education system at Showa period which described in this anime. Dialectical method is used to analyze social factors which contained in this anime as a litperiodry work. This method combines the results of analysis with facts of fiction found in litperiodture and facts in society. Stalcup's theory of education is used to analyze how Japan's educational system affecting those high school students. The results are: 1) changes in education system succeeded in making students to be more active, creative, brave, hard working, and work in team; 2) changes in education system succeeded in increasing student's learning passion and adding insight and understanding of science; 3) changes in education system succeeded in improving Japanese education standard and providing same opportunities for boys and girls to have higher education.
\end{abstract}

Keywords : education system;changes; Showa period

\section{PENDAHULUAN}

Jepang dikenal sebagai negara yang mudah beradaptasi dan berhasil melalui dua perubahan besar dalam sejarah modernnya. Perubahan pertama terjadi setelah Restorasi Meiji pada tahun 1868, di mana bangsa Jepang yang awalnya merupakan bangsa feodal berubah menjadi bangsa modern yang berkembang pesat dengan berkiblat ke Barat. Kemudian, perubahan kedua terjadi setelah Perang Dunia II. Pada saat itu Jepang mampu menyesuaikan diri dengan tatanan dunia baru yang didominasi oleh Amerika Serikat.

Dalam setiap perubahan besar ini, reformasi pendidikan di Jepang tercatat memainkan peran sentral.Setelah Perang Dunia II, reformasi berhasil menciptakan sistem pendidikan Jepangyang lebih egaliter, demokratis, dan meritokratis pada saat bangsa Jepang membutuhkan pekerja terampil pada masa-masa pemulihan pasca perang, dibandingkandenganmasamasasebelummeletusnyaPerangDunia

II(Schoppa, 1991).

Terdapat beberapa karya sastra Jepang yang bercerita mengenai pendidikan, baik berwujud cerpen, novel, komik, maupun film animasi.Komik dan film animasi umumnya diasumsikan sebagai bacaan dan tontonan anak-anak, meskipun pada kenyataannya terdapat 
komik dan film animasi yang dibuat bukan untuk pembaca dan penonton anak-anak. Namun, film animasi yang betul-betul dibuat untuk anak dapat dimasukkan ke dalam genre karya sastra anak (Noviana, 2018).

Salah satu contoh karya sastra yang bermuatan masalah dalam dunia pendidikan adalah film animasi Jepang (anime) berjudul Kokuriko-zaka Kara. Anime yang dirilis di Jepang pada 17 Juli 2011 oleh Studio Ghibli, salah satu studio animasi terbesar di Jepang, ini diproduksi berdasarkan serial komik Jepang (manga) karya Sayama Tetsuro dengan judul sama. Anime berlatar wilayah Yokohama tahun 1963yang termasuk ke dalam zaman Showa ini bercerita tentang upaya para siswa sebuah Sekolah Menengah Atas bernama SMA Konan untuk mencegah penghancuran sebuah bangunan tuaoleh seorang pengusaha lokal yang menjadi penyandang dana SMA tempat mereka bersekolah. Bangunan tua itu sendiri selama ini menjadipusat kegiatan para siswa SMA tersebut yang terdiri dari berbagai klub kegiatan. Sebagai sebuah produk dari Studio Ghibli, maka anime ini dipandang layak untuk dimasukkan dalam kelompok film anak yang merupakan salah satu genre karya sastra anak.

Anime ini dipilih untuk dijadikan sebagai objek material karena bercerita tentang kerja keras para siswa SMA yang tidak mau berdiam diri dalam menyuarakan aspirasi dan mempertahankan sesuatu yang menurut mereka mendukung proses pembelajaran. Hingga pada akhirnya, kerja keras mereka yang dimulai dari nol membawa hasil yang menggembirakan. Hal ini sejalan dengan pendapat Faruk (2014: 46) yang menyatakan bahwa karya sastra bukanlah merupakan hasil ekspresi jiwa, melainkan merupakan cerminan masyarakat, alat perjuangan sosial, serta alat untuk menyuarakan aspirasi dan nasib dari pihak yang menderita dan tertindas.

Selain alasan yang berhubungan dengan isi cerita, sisi produksi anime ini pun cukup menarik untuk diperhatikan. Sutradara Miyazaki Goro menampilkan pandangannya mengenai kehidupan siswa SMA pada zaman Showa dalam film ini dengan sederhana dan lugas, baik yang berhubungan secara langsung maupun tidak langsung dengan dunia pendidikan.

Dalam tulisan ini hanya ada satu hal yang dibahas, yaitu dampak penerapan perubahan pada sistem pendidikan Jepang, khususnya bagi siswa SMA pada zaman Showa seperti yang tergambardalam anime Kokuriko-zaka Kara. Dengan demikian, tujuan dari penelitian ini adalah untuk mendeskripsikan dampak penerapan perubahan pada sistem pendidikan SMA Jepangpada zaman Showa seperti yang tergambardalam anime Kokuriko-zaka Kara.

\section{METODE PENELITIAN}

Metode yang digunakan dalam analisis adalah metode dialektika. Dengan metode ini, faktor sosial yang terkandung dalam karya sastra dapat dianalisis. Metode ini menggabungkan hasil analisis dengan fakta fiksi yang terdapat dalam karya sastra dan fakta yang terdapat dalam masyarakat.

Teori yang digunakan adalah teori sosiologi pendidikan yang dikemukakan oleh R.J. Stalcup (Idi, 2011:13) yang menyatakanbahwa sosiologi pendidikanadalah teori yang menganalisis proses sosiologis yang terdapat di lembaga 
pendidikan. Dalam tulisan ini, sosiologi pendidikan digunakan untuk menganalisis penerapan sistem pendidikan serta dampak-dampak yang ditimbulkan di lingkungan sekolah.

\section{PEMBAHASAN}

\section{1) Sistem Pendidikan Zaman Showa}

Sistem pendidikan adalah suatu sistem yang terdiridari komponenkomponen yang ada dalam proses pendidikan, dimana antara satu komponen dengan komponen yang lainnya saling berhubungan dan berinteraksi untuk mencapai tujuan pendidikan.

Zaman Showa adalah salah satu nama zaman di Jepang pada abad ke-20. Zaman Showa berlangsung pada masa pemerintahan Kaisar Showa atau disebut juga Kaisar Hirohito.Zaman ini dimulai sejak Kaisar Hirohito naik tahta pada tanggal 25 Desember 1926 hingga meninggal pada tanggal 7 Januari 1989.

Pada zaman Showa ini, Jepang mengalami kemajuan pesat dalam berbagai bidang kehidupan termasuk dalam bidang pendidikan. Pasca Perang Dunia II, Menteri Pendidikan Jepang mengumumkan kebijakan pendidikan disusun untuk membangun era Jepang yang baru(Ishii, 2003).

\section{2) Penerapan Sistem Pendidikan ZamanShowa}

Sebelum zamanShowa, sistem pendidikan di Jepang mulanya hanya menerapkan enam tahun wajib belajar. Pada zaman Showa, pemerintah mengubah peraturan menjadi pendidikan wajib belajar selama sembilan tahun yaitu enam tahun sekolah dasar dan tiga tahun sekolah menengah pertama. Pada zaman Showapula, sistem sekolah di Jepang memberlakukan sistem seperti di Amerika, yaitu sekolah dasar selama enam tahun, sekolah menengah pertama selama tiga tahun, sekolah menengah atas selama tiga tahun, dan perguruan tinggi selama empat tahun. Pada tahun 1947, setelah perang dunia II berakhir Jepang mendatangkan ahli-ahli pendidikan dari Amerika, yang kemudian mengubah struktur pendidikan di Jepang menjadi:

a. Sekolah dasar wajib selama enam tahun yang tidak memungut biaya;

b. Sesudah sekolah dasar diadakan sekolah lanjutan pertama selama tiga tahun untuk semua anak laki-laki dan perempuan dengan kurikulum yang sama, dengan tujuan mementingkan perkembangan kepribadian siswa, kewarganegaraan dan kehidupan dalam bermasyarakat;

c. Setelah sekolah lanjutan pertama diadakan sekolah lanjutan atas selama tiga tahun, dan dapat dimasuki baik laki-laki maupun perempuan. Adanya sekolah lanjutan atas memiliki tujuan untuk mengajarkan mata pelajaran yang menyiapkan siswa untuk masuk ke perguruan tinggi dan memperoleh keterampilan kerja (Cummings, 1984: 6-40).

Kurikulum sekolah di Jepang pada zaman Showa ditentukan oleh pemerintah pusat. Di sekolah dasar kurikulum yang diterapkan meliputi pendidikan moral, kegiatan khusus seperti upacara, darmawisata dan pertandingan olahraga. Mata pelajaran yang diajarkan adalah bahasa Jepang, ilmu sosial, ilmu alam, matematika, musik, budi pekerti, kerajinan dan pendidikan jasmani (Cummings, 1984: 154-155).

Sekolah menengah di Jepang menerapkan kurikulum kegiatan 
intrakurikuler dan ekstrakurikuler. Mata pelajaran yang diajarkan adalah bahasa Jepang, ilmu sosial, ilmu alam, musik, kesenian, budi pekerti, seni rupa, teknologi atau kerumahtanggan, dan matematika. Sedangkan kegiatan ekstrakurikuler adalah kegiatan di luar kurikulum yang terdapat di luar jam pelajaran sekolah yang meliputi klub olahraga, drama, musik, kesenian, dan sains (Cummings, 1984: 176-183).

\section{3) Sistem Pendidikan Jepang yang Tergambar dalam AnimeKokuriko Zaka Kara \\ Dalam animeKokuriko-zaka Kara} ada tiga sistem pendidikan Jepang yang digambarkan secara jelas. Tiga sistem pendidikan tersebut dijelaskan sebagai berikut.

\section{1) Diterapkannya kegiatan ekstrakurikuler dalam kurikulum pendidikan Sekolah Menengah Atas}

Sistem pendidikan yang digambarkan pada anime ini adalah sistem pendidikan yang diterapkan pada Sekolah Menengah Atas dengan latar tempat paling dominan adalah Sekolah Menengah Atas Konan. SMAini mempunyai masalah yang berhubungan dengan adanya rencana dewan sekolah untuk menghancurkan sebuah bangunan tua bersejarah dalam lingkup sekolah tersebut, yang dimanfaatkan para siswa untuk melaksanakan kegiatan ekstrakurikuler. Gedung tua tersebut merupakan sebuah club houseatau pusat kegiatan siswa yang bernama Latin Quarter.Di club house ini para siswa SMA Konan melaksanakan berbagai macam kegiatan ekstrakurikuler. Pelaksanaan kegiatan ekstrakurikuler ini merupakan salah satu sistem pendidikan yang diterapkan pada zaman Showa, dimana diharapkan dengan kegiatan ini akan memperluas pengetahuan siswa, mengembangkan nilai-nilai atau sikap dan menerapkan secara lebih lanjut pengetahuan yang telah dipelajari siswa dalam mata pelajaran inti dan pilihan.

Kebijakan pemerintah untuk memasukkan kegiatan ekstrakurikuler dalam sistem pendidikan di sekolah menengah ini telah membangkitkan minat para siswa SMA Konanuntuk masuk dalam kegiatan ekstrakurikuler. Kegiatan ekstrakurikuler telah membangkitkan semangat mereka untuk beraktifitas diluar jam pelajaran sekolah dan telah menumbuhkan rasa cinta yang mendalam terhadap kegiatan luar sekolah, sehingga ketika Dewan Sekolah memutuskan untuk menghancurkan club housetersebut, para siswa SMA Konan berjuang sekuat tenaga untuk mencegah usaha penghancuran tersebut.

Film animasi Kokuriko-zaka Kara banyak menggambarkan pelaksanaan kegiatan ekstrakurikuler. Dua tokoh utama dalam film ini yang bernama Umi Matsuzaki dan Shun Kazama digambarkan sebagai tokoh yang sangat aktif dalam kegiatan ekstrakurikuler. Shun Kazama adalah ketua Klub Literatur yang setiap minggu menerbitkan koran sekolah. Sedangkan Umi Matsuzaki adalah tokoh yang banyak membantu Shun Kazama dalam penerbitan koran tersebut. Begitu juga dengan tokoh tambahan bernama Mizunuma, digambarkan sebagai ketua OSIS SMA Konan yang sangat aktif melaksanakan kegiatan ekstrakurikuler. Ketiga tokoh di atas sangat mencintai kegiatan ekstrakurikuler sehingga mereka berjuang keras agar club house tempat mereka dan teman-teman lainnya 
Kiryoku, Volume 2 No 4, 2018

e-ISSN:2581-0960 p-ISSN: 2599-0497

Tersedia online di http://ejournal.undip.ac.id/index.php/kiryoku

melakukan kegiatan ekstrakurikulertidak jadi dihancurkan.

\section{2) Diselenggarakannya sistem pendidikan modern dengan memasukkan beberapa mata pelajaran dalam kurikulum pendidikan yang diambil dari sistem pendidikan Barat}

Sistem pendidikan zaman Showa yang lainseperti yang digambarkan dalam film Kokuriko-zaka Kara adalah diselenggarakannya pendidikan modern dengan memasukkan beberapa mata pelajaran ke dalam kurikulum pendidikan Jepang, yang pada zaman sebelumnya tidak ada.

Setelah kalah perang dari Sekutu yang dipimpin oleh Amerika pada tahun 1945, Jepang banyak berkiblat ke negaranegara Barat dalam berbagai macam bidang kehidupan, termasuk dalam bidang pendidikan. Salah satu kebijakan baru dalam bidang pendidikan yang dicetuskan oleh Menteri Pendidikan Jepang pada tahun 1945 adalah "Kebijakan pendidikan untuk pembangunan Jepang Baru". Untuk mencapai hal tersebut, dilakukan pembaharuan dalam pendidikan, termasuk perubahan mata pelajaran yang diajarkan pada tingkat sekolah menengah. Mata pelajaran yang diajarkan pada tingkat menengah pada zaman Showa era Pasca Perang Dunia II adalah bahasa Jepang, ilmu sosial, ilmu alam, musik, kesenian, budi pekerti, seni rupa, teknologi atau kerumahtanggaan, dan matematika.

Dalam film animasi Kokuriko-zaka Kara terlihat dengan jelas penerapan sistem pendidikan yang berhubungan dengan mata pelajaran yang dipelajari oleh siswa-siswa sekolah menengah. Banyak mata pelajaran yang dijadikan topik pembicaraan oleh tokoh-tokoh dalam film ini.Berikut adalah beberapa contoh kutipan dialognya.

Kutipan 1.

Guru : Apa yang telah dipahami selama ini oleh Klub Astronomi?

Siswa :Klub Astronomi sudah menyelidiki bintik matahari selama 10 tahun, Pak.

Kutipan 2

Siswa 1 : Klub Astronomi ada di sebelah mana?

Siswa 2 :Klub Astronomi ada di lantai 3.

Kutipan 3

Siswa :KlubKimia, beraninya kalian mengganggu kami.Beri hormat sedikit, hei kamu jurusan kimia kelas dua!

Kutipan 4

Siswa :Sebentar lagi ujian tengah semesterfisika ya.

Kutipan 5

Mizunuma :Kamu adik kelasku. Kamu diajar guru fisika bernama Pak Suzuki?

Kutipan 6

Umi :Semua siswa menanti-nanti ujian matematika bakal sesulit apa.

Kutipan-kutipan tersebut di atas menggambarkan banyaknya mata pelajaran dari negara Barat yang diadopsi oleh pemerintah Jepang pada zaman Showa. Dengan ditambahkannya mata pelajaran dari Barat ke dalam kurikulum pendidikan, Jepang berharap dapat menjadi negara 
maju yang setara dengan bangsa-bangsa Barat.

\section{3)}

\section{Diselenggarakannya Sekolah Lanjutan Atas selama tiga tahun yang dapat dimasuki baik laki- laki maupun perempuan}

Sistem pendidikan zaman Showa lainnya yang digambarkan dalam film ini adalah diselenggarakannya Sekolah Lanjutan Atas selama tiga tahun setelah Sekolah Lanjutan Pertama, yang dapat dimasuki baik oleh siswa laki-laki maupun perempuan. Hal ini bertujuan untuk memberi kesempatan seluas-luasnya baik kepada laki-laki maupun perempuan untuk mendapat hak atas pendidikan yang sama sampai Sekolah Menengah Atas.

Sistem pendidikan ini tergambar jelas diterapkan di Sekolah Menengah Atas Konan yang menjadi latar utama dalam film animasi ini. Pelajar di Sekolah Menengah Atas ini terdiri dari siswa lakilaki dan perempuan. Tokoh utama perempuan bernama Umi dan tokoh utama laki-laki bernama Shun juga merupakan siswa di sekolah ini. Hal ini dapat dilihat dari adegan berikut.

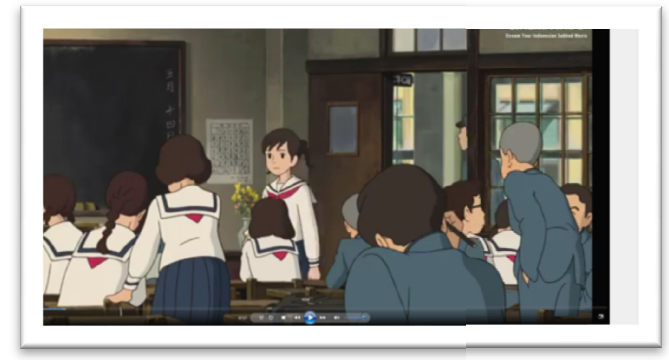

Gambar 1. Suasana di dalam ruang kelas SMA Konan

Gambar tersebut menjelaskan tentang tidak adanya diskriminasi antara laki-laki dan perempuan dalam hak memperoleh pendidikan sampai Sekolah
Menengah Tingkat Atas. Perempuan pun tidak kalah dalam prestasi pendidikan akademis. Tokoh Doktor Hakuto yang muncul dalam film ini digambarkan sebagai tokoh matematika yang sangat jenius yang menjadi kebanggaan Sekolah Menegah Atas Konan. Tokoh Umi Matsuzaki yang menjadi tokoh utama dalam film ini pun tokoh perempuan hebat yang menjadi tokoh kunci dalam menyelamatkan club house yang akan dihancurkan oleh Dewan Sekolah.

\section{4) Dampak penerapan perubahan sistem pendidikan Jepang pada zaman Showa dalam anime Kokuriko-zaka Kara}

Penerapan perubahan sistem pendidikan pada zaman Showa, khususnya pada tingkat SMA, telah memberikan beberapa dampak positif bagiperubahan sikap mental masyarakat Jepang terutama sikap mental siswa-siswanya. Berikut penjelasan dampak tersebut seperti yang tergambar dalam film animasi Kokurikozaka Kara.
a. Diselenggarakannya kegiatan ekstrakurikuler di Sekolah Menengah Atas telah berhasil melahirkan siswa-siswa yang aktif, kreatif, berani, demokratis, pekerja keras, dan mampu bekerja sama

Keaktifan siswa-siswa SMA Konan dalam film ini dapat dilihat dari adegan di mana hampir semua siswa SMA Konna aktif dalam berbagai macam kegiatan ekstrakurikuler dengan menjadi anggota Klub Matematika, Klub Arkeologi, Klub Olahraga, dan klub-klub lain. Siswasiswa SMA Konan pun aktif melakukan 
gerakan untuk menentang penghancuran club house.

Kegiatan ekstrakurikuler juga menjadikan siswa-siswa SMA Konan menjadi siswa yang kreatif. Kreatifitas mereka terlihat dari tokoh Shun Kazama yang sangat kreatif menciptakan puisipuisi indah yang diterbitkan dalam koran mingguan sekolah. Siswa-siswa SMA Konan pun sangat kreatif dalam menciptakan berbagai macam aktifitas untuk mencegah penghancuran club house mereka dengan cara menyelenggarakan debat terbuka bagi seluruh pelajar, memasang berbagai macam spanduk menentang penghancuran club house, dan lain-lain. Tokoh Umi memberi ide kepada Shun agar club house yang selama ini sangat kotor dan berantakan dibersihkan dan direnovasi agar terlihat bersih dan indah, sehingga bisa merubah niat Dewan Sekolah agar tidak jadi menghancurkannya. Ternyata ide Umi berhasil. Setelah dibersihkan dan direnovasi, penghancuran club house tersebut dibatalkan. Berikut kutipan pada saat Umi mengusulkan ide tersebut.

\section{Umi: Bagaimana kalau club house kita bersihkan. Bangunannya memang sudah tua tetapi sangat bagus. Lalu kita ajak para siswa untuk melihat-lihat club house.}

Selain itu, kegiatan ekstrakurikulerini juga telah melahirkan siswa-siswa yang pemberani. Banyak adegan dalam film ini yang menggambarkan keberanian siswa-siswa SMA Konan. Tokoh Shun, Umi, dan Mizunuma digambarkan sebagai tokohtokoh yang berani menentang kebijakan dewan sekolah yang akan menghancurkan club house. Mereka berani menghadap langsung Pejabat Pendidikan pemilik SMA Konan di Tokyo untuk meminta agar $c l u b$ housetidak dihancurkan.

Suka bekerja keras juga merupakan salah satu dampak positif dari kegiatan ekstrakurikuler. Ketika mereka tahu bahwa club house akan dihancurkan, seluruh siswa SMA Konan yang menentang rencana tersebut bekerja keras untuk membersihkan dan merenovasi club house tersebut. Setelah selesai belajar di kelas, mereka beramai-ramai menuju club houseuntuk membersihkan dan merenovasinya.Berkat kerja keras mereka,club house berhasil dibersihkan dan direnovasi sehingga terlihat bersih dan indah.

Bekerja sama juga merupakan salah satu dampak posistif dari kegiatan ekstrakurikuler yang digambarkan dalam film ini.Bekerja sama diperlihatkan pada adegan saat membersihkan dan merenovasi club house. Semua siswa SMA Konan terutama yang aktif dalam kegiatan ekstrakurikuler bekerja sama bergotongroyong membersihkan club house tersebut. Mereka pun bekerja sama dalam upaya menentang penghancuran club house tersebut. Mereka bekerja sama membuat dan memasang spanduk yang bertuliskan tentangpenentangan penghancuran. Mereka juga bekerja sama mempersiapkan penyambutan kedatangan para pengusaha dan pejabat Dewan Sekolah pemilik SMA Konan ke club house, seperti yang ditunjukkan dalam adegan berikut. 


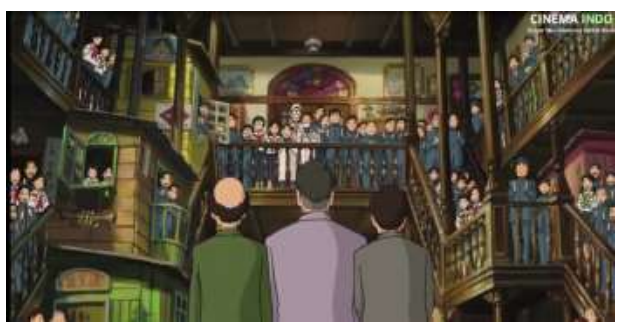

Gambar 2. Suasana penyambutan Dewan Sekolah di club house Latin Quarter

Sikap demokratis pun merupakan salah satudampak positif dari diadakannya kegiatan ekstrakurikuler yang digambarkan dalam film ini. Sikap demokratis diperlihatkan oleh siswa-siswa SMA Konan dengan diselenggarakannya debat terbuka tentang rencana Dewan Sekolah menghancurkan club house. Debat tersebut dipimpin oleh ketua umum club house yang bernama Mizunuma untuk meminta pendapat dari semua pelajar tentang rencana pihak sekolah yang bermaksud menghancurkan club house. Kelompok yang menentang penghancuran club housebermusyawarah dengan kelompok yang pro penghancuran. Meskipun pada akhirnya musyawarah tersebut tidak menghasilkan kesepakatan, namun usaha mereka untuk berkumpul, bermusyawarah, dan mencari jalan terbaik dalam menyikapi rencana penghancuran club house tersebut menunjukkan sikap demokratis.

b. Dimasukkannya beberapa mata pelajaran yang pada zaman sebelumnya tidak dipelajari berhasil meningkatkan minat belajar siswa, memperluas wawasan dan pemahaman terhadap ilmu pengetahuan

Dimasukkannya beberapa mata pelajaran yang pada zaman sebelumnya tidak dipelajari seperti mata pelajaran fisika, kimia dan lainnya telah memberikan dampak positif dengan semakin meningkatnya gairah belajar para siswa dan semakin terbukanya wawasan serta pemahaman terhadap ilmu pengetahuan. Hal ini terbukti dengan banyak dibentuknya klub-klub yang berhubungan dengan mata pelajaran tertentu, karena ketidakpuasan mereka jika hanya belajar di dalam kelas. Mereka membentuk klub matematika, klub kimia, klub fisika, dan klub-klub lain.

Dengan dipelajarinya mata pelajaran baru yang berasal dari Barat pada zaman Showa banyak lahir ilmuwan Jepang yang beberapa orang diantaranya berhasil menerima hadiah Nobel. Salah satunya dalam anime ini digambarkan dengan adanyadoktor perempuan di bidang matematika bernama Dr. Hokuto yang dulunya aktif di klub matematika SMA Konan.

c. Diselenggarakannya Sekolah Lanjutan Tingkat Atas selama tiga tahun bagi laki-laki dan perempuan telah meningkatkan standar pendidikan di Jepang dan memberikan peluang besar, baik bagi laki-laki maupun perempuan, untuk menempuh pendidikan yang lebih tinggi

Kebijakan ini telah berhasil menghapus pandangan bahwa laki-laki lebih berhak untuk memperoleh pendidikan yang lebih tinggi daripada perempuan. Dalam anime ini digambarkan perempuan mempunyai hak yang sama untuk melanjutkan sekolah bersama dengan anak laki-laki sampai Sekolah Menengah Atas, bahkan sampai Perguruan Tinggi. Pelajar perempuan mempunyai hak yang sama dengan pelajar 
laki-laki dalam berbagai macam kegiatan. Bahkan Umi sebagai tokoh perempuan dalam film ini digambarkan sebagai tokoh kunci dalam upaya menyelamatkan clubhouseyang akan dihancurkan oleh pihak sekolah, seperti yang ditunjukkan dalam adegan berikut.

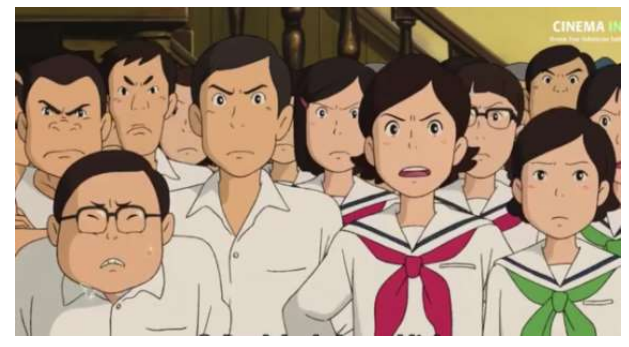

Gambar 3. Siswa laki-laki maupun perempuan bersama-sama mempertahankan club house tempat mereka melaksanakan kegiatan ekstrakurikuler dari rencana penghancuran

\section{PENUTUP}

Penerapan sistem pendidikan baru pada zaman Showa telah memberikan banyak perubahan pada kehidupan masyarakat Jepang. Era baru Jepang telah lahir semenjak diterapkannya sistem pendidikan yang banyak meniru sistem pendidikan Amerika. Jepang yang pada zaman sebelumnya sangat setia dengan sistem pendidikan tradisional mulai menyadari bahwa perubahan sistem pendidikan harus dilakukan bila ingin memperoleh kemajuan seperti bangsabangsa Barat. Perubahan dalam sistem pendidikan pun mulai dilakukan terutama pada zaman Showa pasca Perang Dunia II setelah Jepang kalah melawan Sekutu.

Dampak positif dari perubahan sistem pendidikan tersebut pun mulai dirasakan oleh Jepang. Dalam jangka waktu yang relatif pendek setelah negara mereka hancur akibat kekalahan dalam Perang Dunia II, perlahan-lahan Jepang bangkit dan sekarang Jepang menjadi negara maju yang setara dengan negaranegara maju di Barat. Hal itu tidak terlepas dari sistem pendidikan baru yang diterapkan pada zaman Showa.

\section{DAFTAR PUSTAKA}

Cummings, William K. (1984). Pendidikan dan Kualitas Manusia di Jepang.Yogyakarta: Gadjah Mada University Press.

Faruk. (2014). Pengantar Sosiologi Sastra.Yogyakarta: Pustaka Pelajar.

Idi, Abdullah. (2011). Sosiologi Pendidikan Individu, Masyarakat, dan Pendidikan.Jakarta: PT. Rajagrafindo Persada.

Ishii, Y. (2003). Development Education in Japan; a Comparative Analysis of the Contexts for Its Emergence and Its Introduction Into the Japanese School System. New York: RoutledgeFalmer.

Noviana, F. (2018). Adaptasi Cerpen Chuumon no Ooi Ryouri Ten Karya Miyazawa Kenji Menjadi Anime Karya Shibuichi Setsuko. Japanese Research on Linguistics, Literature and Culture, 1(1), 1-15.

Schoppa, L. J. (1991). Education Reform in Japan. London: Routledge.

Stephens, Michael D. (1991). Japan and Education. London: Macmillan. 